\title{
Influence of Calcium Oxide on Thermal and Mechanical Properties of Recycled Polyethylene Terephtalate / Polyethylene Mixture
}

\author{
Sönmez Maria' ${ }^{1}$, Alexandrescu Laurentia ${ }^{1}$, Georgescu Mihai ${ }^{1}$, Gurau Florentina Dana1, Ficai Denisa², \\ Ficai Anton², Trusca Roxana ${ }^{2}$, Ovidiu Oprea ${ }^{2}$, Ioana Lavinia Ardelean ${ }^{2}$, Constantinescu Doina ${ }^{3}$ \\ ${ }^{1}$ National Research \& Development Institute for Textiles and Leather-Division: Leather and Footwear Research Institute \\ 93 Ion Minulescu St., Bucharest, Romania \\ maria.sonmez@icpi.ro; laurentia.alexandrescu@icpi.ro; mihai.georgescu@icpi.ro; dana.gurau@icpi.ro \\ ${ }^{2}$ Politehnica University of Bucharest, Faculty of Applied Chemistry and Material Science \\ 1-7 Polizu St., Bucharest, Romania \\ denisa.ficai@yahoo.ro; anton.ficai@upb.ro; truscaroxana@yahoo.com; ovidiu73@yahoo.com; dy4_ioana@yahoo.com \\ ${ }^{3}$ SC MONOFIL S.R.L. \\ 1 Uzinei St., Savinesti, Romania \\ monofil.srl@gmail.com
}

\section{Extended Abstract}

The high increase in post-consumption waste, especially from the packaging industry, has prompted scientists to find effective ways to recycle and reuse it. One of the most common polymers used as raw material in the production of disposable bottles is polyethylene terephthalate (PET). PET is a semi-crystalline thermoplastic polyester with optimal physical and mechanical properties-tensile strength, stiffness, hardness, resistance to crack formation, low moisture absorption and thermal expansion $[1,2]$. The physical processing of PET using melt extrusion s considered to be the most advantageous method of recycling compared to the chemical way/incineration because it is simple, it uses common equipment, it is flexible in terms of raw material volume and has a much lower impact on the environment. However, during the reprocessing of PET there are problems related to the level and nature of the contaminants present in the flakes, which negatively affect the physical and chemical properties (acids - act as catalysts for the chain cleavage reactions, water - reduces the molecular weight through the hydrolysis reaction, dyes - present in bottles, and ink-printed labels lead to yellowing of the polymer due to intra-molecular crosslinking and oxidation reactions) [1,3]. Numerous studies in the literature have focused on improving PETr properties by adding: PC in varying proportions (20-50\%) [4], chain extender containing epoxy groups - JONCRYL and impact modifier - LOTADER which is a glycidyl methacrylate terpolymer [5], sawdust wood [6], graphene [7], montmorillonite [8], $\mathrm{CaCO}_{3}$ [9], SEBS-g-AM [10].

The purpose of this paper is to improve the mechanical, thermal and processability properties of the PETr/PE mixture (70 wt/30 wt $\%$ ) by adding various percentages (1,3 and 5\%) of $\mathrm{CaO}$ nanoparticles. To improve the compatibility of PETr / PE, ethylene vinyl acetate copolymer (EVA) was used as compatibilizer at $5 \mathrm{wt} \%$ based on the total amount of polymers. Prior to processing, PETr granules were subjected to a pre-drying process in a hot air oven at $140-150^{\circ} \mathrm{C}$ for about $4-7$ hours to remove the physically adsorbed water. Nanocomposites were obtained on a Brabender mixer at a temperature of 245$254^{\circ} \mathrm{C}$ and a mixing time of 5-7 minutes. From the mixtures obtained, test specimens (for physico-mechanical, morphostructural and thermal determinations) were made by the compression molding method, using an electric press at $190-254^{\circ} \mathrm{C}$, preheating -5 minutes, pressing time $-5-7$ minutes, cooling -15 minutes, pressure $-150 \mathrm{kN}$. The thermal results obtained by DSC demonstrate that the PETr/PE mixture shows a more pronounced thermal stability compared to the results obtained for plain polyethylene. Moreover, in the case of adding EVA compatibility agent, the thermal stability decreases significantly but this is subsequently compensated by the addition of various percentages of $\mathrm{CaO}$ nanoparticles. The hardness of the mixtures also increases progressively with the increase in $\mathrm{CaO}$. Izod shock resistance increases both for EVA mixtures and for mixtures containing $1 \mathrm{wt} \%$ or $3 \mathrm{wt} \% \mathrm{CaO}$. The processability of blends is also improved in the case of blends containing EVA compared to PETr/EVA uncompatibilized mixture due to reduced viscosity in the melt. SEM images obtained for EVA-compatibilized mixtures show a good dispersion of $\mathrm{CaO}$ nanoparticles in PETr/PE mass. 
Keywords: Mechanical And Thermal Property, Recycled PET, Nanopowder, Compatibilization, Cao.

\section{Acknowledgements}

This research was financed through PN-III-P2-2.1-PTE-2016 project: Recovery of recycled thermoplastic polymers by reinforcement with functionalized natural fibres to obtain new added value products, ctr. No. 20PTE/2016, supported by MECS-UEFISCDI.

\section{References}

[1]. A. M. Al-Sabagh, "Greener routes for recycling of polyethylene terephthalate," Egyptian Journal of Petroleum, vol. 25, no.1, pp. 53-64, 2016.

[2]. H. W. Koh, "Advanced recycled polyethylene terephthalate aerogels from plastic waste for acoustic and thermal insulation applications," Gels, vol. 4, no. 43, pp. 1-13, 2018.

[3]. L. M. Pereira et al., "Rheological, morphological and mechanical characterization of recycled poly (ethylene terephthalate) blends and composites," Materials Research, vol. 20, no. 3, pp. 791-800, 2017.

[4]. S. Khoramejadian, "Enhance mechanical and thermal properties of recycled poly ethylene terephtalate (PET) from used bottle," Advances in Environmental Biology, vol. 5, no. 13, pp. 3826-3829, 2011.

[5]. N. G. Karsli, "A study on the fracture, mechanical and thermal properties of chain extended recycled poly(ethylene terephthalate)," Journal of Thermoplastic Composite Materials, vol. 30, no. 8, pp. 1-8, 2017.

[6]. M. F. AL- Obaidi, "Effect of sawdust wood on physical properties of recycled polyethylene terephthalate (RPET)," International Journal of Innovative Research in Science, Engineering and Technology, vol. 4, no. 1, pp. 18443-18441, 2015.

[7]. I. M. Inuwa, S. A. Shamsudin, "Thermal properties, structure and morphology of graphene reinforced polyethylene terephthalate/polypropylene nanocomposites," The Malaysian Journal of Analytical Sciences, vol. 18, no. 2, pp. 466477, 2014.

[8]. K. Majdzadeh-Ardakani et al., "A novel approach to improve the barrier properties of PET/clay nanocomposites," International Journal of Polymer Science, vol. 2017, pp. 1-10, 2017.

[9]. W. Gao, "Effect of calcium carbonate on PET physical properties and thermal stability," Powder Technology, vol. 244, pp. 45-51, 2013.

[10]. L. M. G Araujo et al., "Compatibilization of recycled polypropylene and recycled poly (ethylene terephthalate) blends with SEBS-g-MA," Polimeros, vol. 28, no. 1, pp. 84-91, 2018. 